\title{
Knowledge, Attitudes and Practices of Postpartum Women Regarding Cervical Cancer in Maroua, Northern Cameroon
}

\author{
Dohbit JS ${ }^{1,2}$, Domkao NP2, Meka NUE ${ }^{1,2}$, Belinga $E^{2}$, Joel Noutakdie Tochie ${ }^{3 *}$, Ndjoumemi $Z^{2}$, Ourtching $C^{2,5}$ and \\ Tebeu PM1,2
}

${ }^{1}$ Departement of Gynaecology and Obstetrics, Yaounde Gynaeco-Obstetrics and Paediatric Hospital, Cameroun

${ }^{2}$ Departement of Gynaecology and Obstetrics, University of Yaoundé, Cameroon

${ }^{3}$ Departement of Surgery and Specialities, University of Yaoundé, Cameroon

${ }^{4}$ Foumbot District Hospital, Cameroon

${ }^{5}$ Departement of Gynaecology and Obstetrics, Maroua Regional Hospital, Cameroon

Submission: August 13, 2018; Published: September 06, 2018

"Corresponding author: Joel Noutakdie Tochie, Faculty of Medicine and Biomedical Sciences, University of Yaoundé I, Yaoundé, Cameroon;

Email: joeltochie@gmail.com

\begin{abstract}
Background: Worldwide cervical cancer is a real public health problem representing the third most common cancer and the fourth leading cause of female cancer-related death. In Cameroon it is the second most common cancer in women after breast cancer and the leading cause of cancer deaths in women due to lack of information on this pathology. Few studies have focused on analyzing the influence of knowledge and attitudes on women's practices on how to prevent this cancer.
\end{abstract}

Aim: To determine the knowledge, attitudes and practices of postpatum women with respect to cervical cancer in the health districts of Maroua, northern Cameroon.

Methodology: This was an analytical study carried out in seven maternity units of the Maroua health districts in northern Cameroon from 1 February to 31 April 2018. The target population consisted of postpartum women aged between 25 and 45 years. The data on knowledge, attitude and practices of cervical screening, as well as sociodemographic data were collected on a pre-tested questionnaire. The odds ratio (OR) with its $95 \%$ confidence interval was used to assess the association between the different variables. The threshold of statistical significance was set at P-value $<0.05$.

Result: We recruited a total of 622 postpartum women with a mean age of $28.9 \pm 4.26$ years. Majority of participants were married (69.6\%), housewives (60\%), Muslims (51.5\%), lived in urban areas (66.9\%), had a secondary level of education (31.7\%), and were multiparous (34.2\%). The level of knowledge was unsatisfactory for $73.8 \%$ of participants. Housewives had a 31-fold increased risk to have insufficient knowledge [OR=31.96 (7.206-141.701)]. Christians were 8.421 times more likely to have satisfactory knowledge. Likewise, married women were more likely to have satisfactory knowledge [OR=6.894 (2.389-19.894)]. Despite 73.8\% participants having unsatisfactory knowledge on, 96.6\% had favorable attitudes. Women with poor knowledge had a 20-fold increase in having favorable attitudes [p=0.003 $0 R=20.149(2.764-146.881)]$. Practices were poor in $97.4 \%$ of the women. Compared to women with good knowledge, those with poor knowledge have a higher risk for poor practices regarding cervical screening [OR=33,673 $(4,273-265,421)]$. The level of attitudes did not seem to influence the level of practice.

Conclusion: The postpartum women in Maroua appear to have unsatisfactory knowledge on cervical cancer. However, they seem to adopt favorable attitudes with regards to its screening, although they portray poor practices.

Keywords: Knowledge; Attitudes; Practices; Cervical Cancer

\section{Introduction}

Cervical cancer is a slow-growing cancerous disease that generally takes several years to undergo malignant transformation, from primary infection by the oncogenic human papillomavirus (HPV) to the various precancerous histological

lesions accompanying the persistence of the infection [1]. Globally, this cancer is a public health threat. Worldwide, it is ranked the $3^{\text {rd }}$ most common malignancy after breast cancer and colorectal cancer, the $10^{\text {th }}$ most common cancer in developed countries and in developing countries, it is the $2^{\text {nd }}$ most common 
cancer after breast cancer. About 530000 new cases of cervical cancer occur annually [2]. It is the 4th leading cause of death in the world after colorectal cancer, lung cancer and breast cancer, with $85 \%$ of cervical cancer-related deaths occurring in developing countries. In 2012, the estimated global mortality from cervical cancer was 275,000 deaths [2]. Cervical cancer accounts for $9 \%$ of all women's cancers [3] and $8 \%$ of all cancer deaths [4].

In Cameroon, cervical cancer represents the 2nd most encountered gynecological cancer after breast malignancy and the 1st cause of cancer deaths in women [5]. Its incidence is estimated at 40/100000 woman-years and the average age at diagnosis is 49 years. According to GLOBOCAN 2012, the incidence of cervical cancer in Cameroon is 80.73/100,000 women [6]. Organized screening for cervical cancer by cytology and the treatment of precancerous lesions has allowed developed countries to drastically reduce the incidence and mortality of this cancer [7]. However, in Cameroon and other developing countries, the incidence of cervical cancer remains high and patients often present late, with advanced cancer stages at the time of diagnosis [8]. In these resource-poor countries, there is no systematic screening program for cervical cancer. Screening is selective, opportunistic or sporadic in the form of campaign. Inadequate financial resources, weak health systems and limited numbers of skilled practitioners are the main reasons for low coverage of cervical cancer screening in most low- and middleincome countries [9]. Cervical cancer is a real public health problem in Cameroon. To know the methods of prevention of this pathology in order to reduce its incidence and the mortality, we proposed this study aimed at determining the knowledge, attitudes and practices of postpartum women vis-à-vis cervical cancer in the health districts of Maroua, Northern Cameroon.

\section{Methods}

\section{Study design and setting}

This was an analytical KAP study carried out between October 1, 2017 to May 31, 2018 in all of the three health districts of Maroua in the Far-north region of Cameroon and involved seven randomly chosen maternity units (out of 29 health facilities) of the following hospitals; the integrated health centre of Domayo Djarma, the integrated health centre of Ourotchédé, the Catholic Sisters integrated health centre, the sub-divisional hospital of Founangué, the integrated health centre of Zokok, the Maroua regional hospital and the integrated health centre of Djarengolkodek.

\section{Study participants, sampling and variables}

Our target population was all consenting consecutive women aged between 25 and 45 years who had given birth in the aforementioned health facilities during the study period. The independent variables were age, residence, religion, marital status, level of education, occupation, and parity. The dependent variables were:
Knowledge: having heard about cervical cancer, sources of information, its causative agent, its signs or symptoms, consequence, means of prevention and management.

Attitudes: feelings towards cervical cancer screening, desire to carry out a voluntary screening test or not.

Practices: have done the screening test before, willingness to carrying out of the screening, number of screening test done and frequency, reason for not carrying out the screening.

\section{Data analysis}

The statistical analysis was done using the software Epi Info 7.2.2.6, SPSS and Microsoft Excel 2016. We used the chisquare test to assess the homogeneity of distribution of the study population. The odds ratio (OR) with its $95 \%$ confidence interval was used to assess the association between the different variables. The threshold of statistical significance was set at p-value $<0.05$.

\section{Result}

\section{General characteristics of the study population}

In the present study, all 622 postpartum women approached consented to partake into the study, hence, a $100 \%$ response rate. Majority of the participants were interviewed at the regional hospital (30.4\%), followed by the integrated health centre of Djarengolkodek with $21.1 \%$ respondents. The mean age of our participants was $28.9 \pm 4.3$ years (range: $25-45$ years) more than half $(64.3 \%)$ being aged between 25 to 30 years. The majority of these participants were legally married (69.6\%), while $25.9 \%$ lived in a common-law relationship. Most of them were housewives $(60.0 \%), 31.7 \%$ were secondary school students, $25.9 \%$ primary, $16.9 \%$ university and $25.6 \%$ were school dropped out. With regards to their site of residence, $66.9 \%$ lived in urban areas and $33.1 \%$ in rural areas. The Muslim religion was the most represented at $51.5 \%$ and $48.2 \%$ were Christians. More than one-third of participants had were multigravidas (37\%) and multiparous (34.2\%).

\section{Knowledge of poetpartum women regarding Cervical Cancer}

In our series, $68.2 \%$ had never heard of cervical cancer, only $31.8 \%$ have heard of it. The most common means of information was the media in $26.6 \%$. Only $5.5 \%$ had heard of cervical cancer in the hospital. Other means of information such as school, the internet and posters globally accounted for 5.9\%. Up to $94.5 \%$ of the participants sample did not know the cause of cervical cancer alone. Just 3.9\% reckon HPV as the real cause of cervical cancer, while $1.6 \%$ attributed its aetiology to magico-religious causes. More than two-third (87\%) did not know the risk factors for cervical cancer and only $14 \%$ rightly cited its risk factors.

About one-fifth $(21.1 \%)$ reported that it is not a sexually transmitted disease, $74.7 \%$ did not know it could be transmitted through sexual intercourse and only $4.2 \%$ said it was a sexually 
transmitted disease. Only $14.9 \%$ claimed to know the clinical manifestations of cervical cancer. About $11.3 \%$ reported that the first is vaginal bleeding and $11.9 \%$ said they knew the consequences, while $9.8 \%$ reported death as its consequence.

Almost one-quarter (24.4\%) knew that cervical cancer could be prevented, $70.8 \%$ did not know and $4.7 \%$ said that you cannot prevent cervical cancer. Another $26.3 \%$ could enumerate the preventive methods of this cancer, mainly through early detection of precancerous lesions as reported by $16.1 \%$.

As much as $81.5 \%$ did not know that there is a vaccine to prevent cervical cancer; $8.7 \%$ said that the vaccine does not exist and only $9.8 \%$ knew that there is a vaccine against cervical cancer. More than half (69.3\%) did not know that it is a curable disease alone. While $27.2 \%$ knew that this cancer can be treated and $3.5 \%$ reported that it is has no cure. Up to $71.7 \%$ did not know that cervical cancer can be permanently cured, however, $22.3 \%$ knew that this cancer can be permanently cured. Table 1 illustrates the level of knowledge of participants.

Table 1: Level of knowledge of participants.

\begin{tabular}{|c|c|c|}
\hline \multirow{2}{*}{ Level of knowledge } & \multicolumn{2}{|c|}{ Participants } \\
\cline { 2 - 3 } & $\mathbf{2}$ & $\mathbf{N}=\mathbf{6 2 2}$ \\
\cline { 2 - 3 } & $\mathbf{N}$ & $\mathbf{\%}$ \\
\hline Poor & 459 & 73.8 \\
\hline Moderate & 146 & 23.5 \\
\hline Satisfactory & 17 & 2.7 \\
\hline Excellent & 0 & 0 \\
\hline
\end{tabular}

The evaluation of the level of knowledge shows that $73.8 \%$ of the respondents had poor knowledge, $23.5 \%$ had an moderate knowledge and only $2.7 \%$ were satisfactory. The level of knowledge could be divided into two categories, namely;

a) Unsatisfactory (poore and moderate $\mathrm{N}=605$ )

b) Satisfactory (satisfactory and excellent $\mathrm{N}=17$ )

\section{Attitudes of poetpartum women with respect to Cervical Cancer}

The analysis shows us that $91.5 \%$ would go to the hospital to care for them if they were to have cervical cancer; amongst which $79.9 \%$ would seek a gynecologist and $11.6 \%$ a general practitioner. On the one hand, $85.3 \%$ believed that screening for cervical cancer is important and helps prevent cervical cancer. Only $19.1 \%$ did not know the important of a cervical cancer screening test. More than half (67.9\%) were indifferent to cervical cancer screening because they perceived that "cervical cancer is like any other disease". Meanwhile, 16.4\% were would not undergo screening for fear of the procedure and results.

On the other hand, $87.8 \%$ wanted to have cervical cancer screening because: "You need to know your status to get better care soon". In contrast, $3.9 \%$ and $8.4 \%$ refused screening because they did not asked their husbands' permission and perceived the price of screening to be very expensive, respectively. More than two-third $(79.8 \%)$ wished to start free screening campaigns in Maroua, while $19.2 \%$ did not know (Table 2).

Table 2: Attitudes of postpartum regarding women cervical cancer.

\begin{tabular}{|c|c|c|}
\hline \multirow{2}{*}{ Attitude Score } & \multicolumn{2}{|c|}{ Participants } \\
\cline { 2 - 3 } & $\mathbf{2}$ & $\mathbf{N}=\mathbf{6 2 2}$ \\
\cline { 2 - 3 } & $\mathbf{N}$ & 0 \\
\hline Harmful & 21 & 3.4 \\
\hline Insufficient & 8 & 1.3 \\
\hline Satisfactory & 593 & 95.3 \\
\hline Positive & 5 & \\
\hline
\end{tabular}

We found that $95.3 \%$ of the participants had a satisfactory or positive attitude, $3.4 \%$ had an insufficient attitude and $1.3 \%$ had a satisfactory approximate attitude.

a) Unfavorable (harmful and insufficient: $\mathrm{N}=21$ )

b) Favorable (Approximate and Satisfactory: N=601).

\section{Practices of poetpartum women with respect to Cervical Cancer}

Of all the women interviewed, we only had 16 (2.6\%) who had cervical cancer screening at least once. The mean age at screening was $28.3 \pm 4.4$ years with a median of 28 years.

Of those who tested for cervical cancer, 15 (2.4\%) received their results; only $2(12.5 \%)$ had twice been screened for cervical cancer.

Of those who had never been screened, 507 (83.7\%) reported that cervical cancer screening was not performed "I have never heard of cervical cancer screening" $12.4 \% \mathrm{n}$ have not had the opportunity to do so (Table 3).

Table 3: Practice of postpartum regarding women cervical cancer.

\begin{tabular}{|c|c|c|}
\hline \multirow{2}{*}{ Practice } & \multicolumn{2}{|c|}{ Participants } \\
\cline { 2 - 3 } & \multicolumn{2}{|c|}{$\mathrm{N}=622$} \\
\cline { 2 - 3 } & $\mathrm{N}$ & 0 \\
\hline Harmful & 0 & 97.4 \\
\hline Inadequate & 606 & 2.6 \\
\hline Satisfactory & 16 & 0 \\
\hline
\end{tabular}

The practices were inadequate in $97.4 \%$ of the cases. Only $2.6 \%$ had a satisfactory practice.

The level of practice could be divided into two categories, namely

a) $\mathrm{Bad}$ (harmful and inadequate $\mathrm{N}=606$ )

b) Good (adequate $\mathrm{N}=16$ ).

\section{Influence of the sociodemographic profile on knowledge}

The unified analysis shows that age groups, residence and reproductive history have no statistically significant influence on knowledge because the P value> 0.05. On the other hand, there is a statistically significant influence between level of education, 
religion, marital status and occupation, and level of knowledge $(\mathrm{P}<0.05)$.

The logistic regression shows that the age group of 25-30 years had 3 times the chance of having unsatisfactory knowledge $[p=0.01,0 R=3.343$ (1.189- 9.394)]. Other professions were fortunate enough to have a satisfactory level of knowledge of cervical cancer. These results are statistically significant for housewives whose likelihood for unsatisfactory knowledge was increased by 31-fold $[\mathrm{p}<0.05$ OR $=31.956$ (7.206-141.701)]. There is no association between the level of education and the level of knowledge but the test was statistically significant with a $\mathrm{p}=0.003$. There is a statistically significant association between marital status and satisfactory knowledge of women given cervical cancer. Being a married woman allowed for a satisfactory knowledge [p<0.001 OR=6.894 (2.389-19.894)] (Table 4).

Table 4: Influence of knowledge attitudes.

\begin{tabular}{|c|c|c|c|c|c|}
\hline \multirow{3}{*}{ Knowledge } & \multirow{2}{*}{$\begin{array}{c}\text { Total } \\
\mathrm{N}=622\end{array}$} & \multicolumn{4}{|c|}{ Attitudes } \\
\hline & & Favourable & Unfavorable & OR (IC à 95\%) & p Valeur \\
\hline & & N (\%) & N (\%) & & \\
\hline Poor & 605 & $403(87.8)$ & $56(12.2)$ & $1 \mathrm{r}$ & \\
\hline Acceptable & 146 & $145(99.3)$ & $1(0.7)$ & $\begin{array}{c}20.149(2.764- \\
146.881)\end{array}$ & $0.003^{* * *}$ \\
\hline Satisfaisante & 17 & $17(100)$ & $0(0)$ & -------- & \\
\hline
\end{tabular}

OR: odds ratio; IC: confidence interval; $1 \mathrm{r}=$ reference category.

Christian women had 8 times the chance to have a satisfactory knowledge of cervical cancer and the test was statistically significant $(\mathrm{p}<0.05,0 R=8.421$ [1.909-37.142]).
This table shows that mothers with poor knowledge had 20,149 times the chance of having favorable attitudes, and this association was statistically significant because $\mathrm{p}<0.05 ; \mathrm{p}=0.003$; OR=20.149 [2.764-146.881] (Table 5).

Table 5: Influences of Knowledge and Attitudes on Practices of cervical screening.

\begin{tabular}{|c|c|c|c|c|c|}
\hline \multirow{4}{*}{ Performances } & \multirow{2}{*}{ Total } & \multicolumn{4}{|c|}{ level of Pratices } \\
\hline & & Good & Poor & & \\
\hline & $\mathrm{N}=622$ & $\mathrm{~N}=16$ & $N=606$ & OR (IC à 95\%) & Valeur $\mathbf{P}$ \\
\hline & & N (\%) & N (\%) & & \\
\hline \multicolumn{6}{|l|}{ Knowledge } \\
\hline Poor & 459 & $1(0.2)$ & $458(99.8)$ & $1 \mathrm{r}$ & \\
\hline Moderate & 146 & $10(6.8)$ & $136(93.2)$ & $33.676(4.273-265.421)$ & $0.001^{* * *}$ \\
\hline Satisfactory & 17 & $5(29.4)$ & $12(70.6)$ & $190.833(20.680-1760.970)$ & $<0.001^{* * *}$ \\
\hline \multicolumn{6}{|l|}{ Attitudes } \\
\hline Favourable & 565 & $16(2.8)$ & $549(97.2)$ & ---- & \\
\hline Unfavourable & 21 & $0(0)$ & $57(100)$ & $1 \mathrm{r}$ & 0.998 \\
\hline
\end{tabular}

Women who had poor knowledge seemed to have poor practices because their chances were multiplied by 33 this association was statistically significant $[p=0.001 ; 0 R=33.676$ (4.273-265.421)]. We did not find an association between attitudes and practices

\section{Discussion}

This study aimed to determine the knowledge, attitudes and practices of postpatum women with respect to cervical cancer in the health districts of Maroua in northern Cameroon. Overall, participants had unsatisfactory knowledge on cervical cancer. Although they portrayed poor practices, they adopted favorable attitudes with regards to its screening.

A total of 622 postpartum women were included in present study. We found that the average age of the women was $28.9 \pm$ 4.26 years, with extremes of 25 to 45 years, and the highest age group being 25 to 30 years old. Our results are slightly higher than those of Mohamed $\mathrm{H}$ et al. in Tunisia in 2003, who observed a mean age of $25.01 \pm 1.45$ years justified by the fact that the study was conducted on young undergraduate medical students. Our mean age is however, slightly lower than the 32.8 years and 36.5 \pm 9.7 years observed by Mbongo et al. [10] in Brazzaville and Mona et el in Congo, respectively. These can be justified by the fact that their studies targeted all women with no age restrictions.

We found that the most represented level of education was secondary school in $31.7 \%$. Other authors have reported data comparable to ours. This is exceeding lower compared to the 50.46 to $63.9 \%$ of secondary school participants reported by authors from similar low-income settings [11-13]. Again, this could be explained by the age restriction of our study population between 25 to 45 years. Meaning we had a more elderly population as evident by its mean age of $28.9 \pm 4.26$ years, an age at which many women have completed secondary education. 
In contrast to Narayana et al. [13] in India, we observed that majority of women (66.9\%) delivered in urban areas. This could be explained by the fact that the study setting, the Bathalapali hospital of Narayana et al. [13] was located in rural area of Southern India.

Similar to Adeka et al. in Nigeria and Mona et al. in Congo who Majority of participants (69.6\%) were married. This concurs with findings made by Adeka et al. in Nigeria and Mona et al. in Congo, who had a married studied population varying between 84.3-89.3\% [11].

Unlike Narayana et al. [13] in India who had a minute proportion of Muslims (27.3\%), our study population was mostly represented by Muslim women in 51.5\%. This difference could be explained by the fact that undue religion is more represented in India.

This study shows that $60 \%$ of participants were housewives, corroborating with results obtained by Tebeu et al. [12] in Maroua, Cameroon. This may be explained by the fact that the Far North region (the study setting) is an area of Cameroon where early marriage and under-enrollment prevail, especially for girls. Hence, females often do not attend higher level of education, which hinders them from exercising a professional job later.

In the present study, only $31.8 \%$ have heard of cervical cancer. By contrast, Mahoungou et al. [10] in the Congo found that $78.6 \%$ of women have heard about cervical cancer. This difference could be justified by the fact that it is common for women of Maroua, Cameroon not to be interested in health information and that the actors in the field of awareness have not undergone sensitization training on this pathology. Thus, the lack of name of cervical cancer in the local language.

The causes and risk factors of cervical cancer were less well known amongst postpartum women with, only 5\% reporting to know the exact aetiology and $6.3 \%$ knowing the risk factors. This observation differs from those of Ali-risasi C et al. [14] in Congo and Tran NT et al. [15] in Korea who found 19.3\% and $28.8 \%$ respectively women who knew the cause of this gynecology malignancy. This may infer inadequate health education or sensitization campaigns on this pathology in the Maroua health districts.

The assessment of the level of knowledge reveals that most of the women interviewed had very poor knowledge, $73.8 \%$. Our result is similar to that of Tebeu et al. [12] in Maroua (Cameroon) who found that $72 \%$ of women in this locality had poor knowledge of cervical cancer. This can be justified by the fact that women in this region are less informed and unaware of this pathology, which represents a public health problem in Cameroon. These results are close to those of Mahoungou F et al. [10] and Ali-risasi C et al. [14] in Kinshasa who found insufficient knowledge of cervical cancer in Congo. All are justified by the fact that these countries are in areas where this pathology is less known. Contrarily, Narayana G et al. [13] in India observed that women had a good knowledge of cervical cancer, which could be explained by the fact that India is a middle-income country compared to Cameroon, a low-income country. Hence, India could have a more robust program to inform women on this pathology as well as to manage this pathology.

Our study showed that $96.6 \%$ of participants had a favorable attitudes towards cervical cancer which can be explained by the fact that these women globally consider all cancers as a very dangerous disease, hence, they prefer its prevention. On the other hand, women's attitudes towards cervical cancer in Kinshasa were poor [14]. This could be explained by the fact that Congolese women were not much interested in their state of health.

In the current study, women's practices towards cervical cancer screening was poor in $97.4 \%$, propably explained by the fact that they did not have adequate awareness "I did not do the screening because I have never heard of it". Interventions to improve on their awareness and practices may include routine health education and screening of cervical cancer to all volontary pregnant women during antenatal care. Our findings corroborate with those of Mbongo et al. [10] who found that only 4.8\% of women had Pap smear. This results re-iterates the fact that there is no program for the fight against gynecological cancers in developing countries.

Our results showed that the age group 25-30 years had a 3 -fold increase in likelihood for unsatisfactory knowledge while housewives had 31-fold increase. As expected, the age group 2530 years was made up of women with a low level of education and given that early marriage is a common culture in northern Cameroon, these may explain their unsatisfactory knowledge towards cervical cancer. The other professions had satisfactory knowledge of cervical cancer. There was a statistically significant association between marital status and satisfactory knowledge of women with regards to cervical cancer. Being a married woman conveyed satisfactory knowledge $[\mathrm{p}<0.001$ OR=6.894 (2.389-19.894)]. This association can be justified by the fact that the brides could be assisted by their husbands in obtaining information about this pathology.

In the logistic regression we found that the mothers with poor knowledge stood 20 times the likelihood to have favorable attitudes. This association was statistically significant with $\mathrm{p}<0.05$ value $[\mathrm{p}=0.003 ; \mathrm{OR}=20.149$ (2.764-146.881)]. This could be justified by the fact that despite ignorance of these mothers they want to have a healthy life.

Women who had poor knowledge seemed to have poor practices because their chances were multiplied by $33[\mathrm{P}=0.001$; $\mathrm{OR}=33.676$ (4.273-265.421)]. We did not find an association between attitudes and practices. All these may be explained by the lack of awareness of this category of women.

We acknowledge some drawbacks of this study. These include the difficulties for the native participants of the Farnorth region of Cameroon to comprehend the meaning of cervical cancer in their local language, "fufuldé". Also, being a qualitative 
study, the interpretation of questions were subject to errors by the participants. However, this study used a large sample size $(n=622)$ and robust analysis to contribute to the scarcity of data available on knowledge, attitude and practices of cervical cancer, a major public health problem in Cameroon.

\section{Conclusion}

Overall, the women of the three different health districts of Maroua had unsatisfactory knowledge, favorable attitudes and bad practices vis-à-vis cervical cancer. The level of knowledge seemed to influence the attitudes of these women. Best practices were related to good knowledge of cervical cancer. The practice did not seem to be influenced by attitudes.

\section{References}

1. Bosch FX, Manos MM, Munoz N, Sherman M, Jansen AM, Peto J, et al. (1995) Prevalence of human papillomavirus in cervical cancer: a worldwide perspective. J Natl Cancer Inst 87(11): 796-802.

2. Jacques F, Hai-Rim S, Freddie B, David FC, Donald MP (2008) Estimates of worldwide burden of cancer in 2008, GLOBOCAN, pp. 1-3.

3. Jemal A, Bray F, Ferlay J (1999) Global Cancer Statistics: 2011. CA Cancer J Clin 49(2): 133-164.

4. Bordonaro M, Lazarova DL, Augenlicht LH, Sartorelli AC (2002) Estimates of the world-wide prevalence of cancer for 25 sites in the adult population. Int J Cancer 97(1): 72-81.

5. Sando Z, Fouogue JT, Fouelifack FY, Fouedjio JH, Telesphore E, et al. (2014) Profil des cancers gynécologiques et mammaires à Yaoundé Cameroun 17: 28

6. Ferlay J, Soerjomataram I, Dikshit R, Eser S, Mathers C, et al. (2015) Cancer incidence and mortality worldwide: Sources, methods and major patterns in GLOBOCAN 2012. Int J Cancer 136(5): E359-86.

7. WHO (2013) Guidelines for screening and treatment of precancerous lesions for cervical cancer prevention. WHO Guidel, pp. 60.

8. Robyr R (2002) Etude pilote de dépistage du cancer du col de l' utérus dans une région rurale camerounaise Thèse, pp. 80.

9. Waggoner SE, Darcy KM, Fuhrman B, Parham G, Lucci J, et al. (2006) Association between cigarette smoking and prognosis in locally advanced cervical carcinoma treated with chemoradiation: A Gynecologic Oncology Group study103(3): 853-858.

10. Mahoungou F, Koulimaya G (2017) Research article connaissances, attitudes et pratiques des femmes en matière de dépistage du cancer du col de l' utérus au centre hospitalier et universitaire de brazzaville * mbongo.

11. Al M, Mohamed FA (2009) Knowledge, Attitudes, and Practice Related to Cervical Cancer Screening, pp. 35-42.

12. Tebeu P, Major AL, Rapiti E, Petignat P, Bouchardy C, Sando Z (2008) The attitude and knowledge of cervical cancer by Cameroonian women; a clinical survey conducted in Maroua, the capital of Far North Province of Cameroon, 761-765.

13. Narayana G, Suchitra MJ, Sunanda G, Ramaiah JD, Kumar BP, et al. (2017) Knowledge, attitude, and practice toward cervical cancer among women attending Obstetrics and Gynecology Department: A cross - sectional, hospital - based survey in South India 54(2):481-487.

14. Ali-risasi C, Mulumba P, Verdonck K, Broeck D Vanden, Praet M (2014) Knowledge, attitude and practice about cancer of the uterine cervix among women living in Kinshasa, the Democratic Republic of Congo 14(1):30.

15. Tran NT, Taylor R, Choe S Il, Pyo HS, Suk O, et al. (2011) Knowledge, Attitude and Practice (KAP) Concerning Cervical Cancer and Screening among Rural and Urban Female Healthcare Practitioners in the Democratic People's Republic of Korea 12(11): 3023-3028.

\section{Your next submission with Juniper Publishers will reach you the below assets}

- Quality Editorial service

- Swift Peer Review

- Reprints availability

- E-prints Service

- Manuscript Podcast for convenient understanding

- Global attainment for your research

- Manuscript accessibility in different formats

( Pdf, E-pub, Full Text, Audio)

- Unceasing customer service

Track the below URL for one-step submission https://juniperpublishers.com/online-submission.php 